\title{
Developing the Cultural Tourism of Ban Phu Village in Thailand
}

\author{
Jiaxiu Liu, Pat Kotchapakdeea, and Homhuan Buarabha
}

\begin{abstract}
Ban Phu is one of the minority village of Phu Thai in northeastern of Thailand, which has history of over 130 years. The Phu Thai people have multicultural heritage. This paper aims to introduce the cultural resources of Ban Phu Village, analyze the tourist supply and market development prospect of Ban Phu, and further illustrate the importance of cultural tourism in modern tourism industry. In addition, this paper provide an insight into the developing tourism market for Ban Phu Village through a cultural tourism perspective. And finally to find the problems of cultural tourism in Ban Phu through the comparison of tourism demand and tourism supply, and put forward some suggestions for development of local tourism.
\end{abstract}

Index Terms - Cultural tourism, market, tourist supply, tourist demand, Ban Phu.

\section{INTRODUCTION}

With the improvement of people's living standards, people will have more and more diverse interests, and travel will develop to be more about the experience and participation. As a subset of travel, cultural tourism is tourism that focuses on a country or region's culture, specifically the lifestyle, art, the history, religion, architecture in those geographical areas and other elements that helped shape their way of life. Cultural tourism is a very complex segment of the "tourism industry", its supply is diverse and versatile. However, the concept of cultural tourism is very complex and even a controversial issue among scholars about its definition and conceptualization. To date, it is the absence of a uniformly accepted definition of the term "cultural tourism". From the more recent perspective we intend to highlight the definition of Richards (1996) who states cultural tourism as "the movement of persons to cultural attractions away from their normal place of residence, with the intention to gather new information and experiences to satisfy their cultural needs" [1]. In general, cultural tourism includes tourism in urban areas, particularly historic and cultural facilities such as museums and theaters. It can also include tourism in rural areas showcasing the traditions of indigenous cultural communities (i.e. festivals, rituals), and their lifestyle, as well as niches like industrial tourism and creative tourism. Nowadays, cultural tourism is becoming more popular throughout the world, which can play an important role in regional development [2] .

Nowadays, visitors are seeking a more authentic experience, so cultural tourism is perceived as a growing

Manuscript received June 19, 2018; revised September 11, 2018.

The authors are with the Khon Kaen University, Thailand (e-mail: linsm198@163.com). market. Tourism market gets involved in the demand of tourists and the supply of markets, which is affected by the sociocultural, environmental and economic factors [3]. Tourism market generally includes all organizations or companies that provide a product, a service or an experience for leisure and learning, even good business, as well as looking for a sense of it within themselves [4]. In present's world tourism is no more a basic sightseeing. In order to be able to understand the complex and dynamic nature of the contemporary tourism experience many researchers utilize the concept of a tourism system, which consists of consumption and production and the experiences that are generated. Therefore, the 'tourism system' becomes an expression of the interaction between demand and supply, which is often used but seldom precisely defined [5].

The world tourism industry is also growing very fast, which has become one of the leading factors to affect the economic development, especially in developing countries [6]. At present, there are many people who are engaged in tourism in the developed world, and increasingly in developing countries.

As one of the minority of Thailand, recently the cultural resource of Ban Phu has been paid sufficient attention by the tourism market. Ban Phu is a Phu Thai community located in Ban Pao Sub-district, Nong Sung District, Mukdahan Province, Thailand. It is famous for its tourism mode of home-stay. Besides of good climate and beautiful natural environment, Ban Phu Village has diverse characteristic cultural resources that comprised to be the tourism supply. Although Ban Phu is a small village in Northeastern Thailand, it receives about 10,000 visitors every year [7].

\section{METHODOLOGY}

The paper seeks to identify the importance of cultural resource in Ban Phu tourism. For this purpose, this study applies three methodology and results can help tourism policymakers in the process of creating an optimal set of sustainable development measures and activities for selective tourism destination. First, literature scan was conducted and applied research about supplies of Ban Phu in cultural tourism were evaluated. Following the review of literature, within the scope of a questionnaire, the participants were requested to answer some items. Finally, real-time data collection was mainly based on in-depth interviews (directed towards local people and experts), participant observations of several events and gatherings hosted by the community and secondary sources (provincial web-site and archive, official press release, public reports). The interview was conducted in two periods, the first period is from November to December 2015, and the the second period from August to 
October 2017. The population of the study consisted of the Ban Phu Villagers, head of community as well as the representatives of public sectors such as Tourism office of the province, and the Cultural office. Moreover, the researchers checked for triangulation of different data sources in order to obtain more robust evidence. Descriptive Analysis was applied to comprehend the final data.

\section{RESULTS AND DISCUSSION}

\section{A. The Tourism Supply of Ban Phu}

1) History of Ban Phu: The Ban Phu Village has a history of over 130 years. In the past, Ban Phu was part of Nong Sung. They migrated from Kham Aw Khiaw and Wang in Laos during the reign of King Rhama 3 in the year of 1844. In the year 1881 some villagers from Nong Sung migrated to live on the bank of the Bang-I Creek. However, there was a flood and many of the people contracted dysentery causing them eat less. Around 20 of the families led by Mr. Suphosombat, Mr. Mahasana, and Mr. Kittirat migrated to the right bank of Krabaen Creek and to a local vegetable field where the leader, Mr. Noon already lived. He called the area Ban Lup Phu. They made Mr. Suphosombat the leader [7]. After around 30 years they moved to another small mountain, which is modern-day Ban Phu. By the year 2017, the Phu Thai population of Ban Phu Village is about 1150.

The Phu Thai language is spoken in Ban Phu Village. Speakers of the Phu Thai language in Thailand can be found mainly in the areas around Mukdahan, especially Khamcha-i District, Nakhon Phanom, Ubon Ratchathani, Kalasin and Sakon Nakhon. Phu Thai speakers live as well in the Khammouane, Savannakhet provinces of Laos. Some speakers have been reported in Saravan, and Champassak provinces of Laos, northern areas of Vietnam, and possibly also in China [7].

The natural environment Ban Phu is bordered with Roi Et Province and neighbored with Mueng Mukdahan District. It is $6 \mathrm{~km}$ away from the Nong Sung District and about 800 $\mathrm{km}$ away from Bangkok. Ban Phu's climate is characterized by the tropical monsoon with sufficient sunshine and heat. The average temperature is about $22^{\circ} \mathrm{C}$, with the lowest of $7{ }^{\circ} \mathrm{C}$ and highest $40{ }^{\circ} \mathrm{C}$. It is coldest in December and January, and warmest in April and May [7].

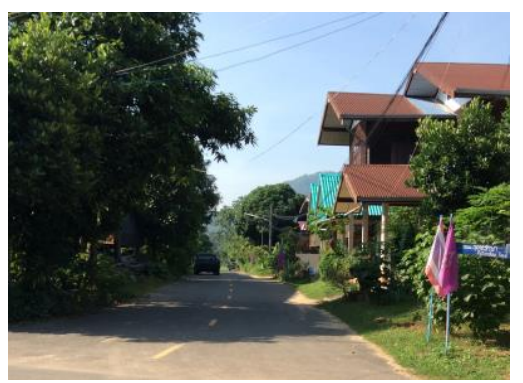

Fig. 1. Natural environment of Ban Phu.

The Ban Phu Village is seated near the mountains and river. There are forests near the village and lots of trees are planted inside of the village as well (Fig. 1). The weather is neither too hot nor too cold. However, the temperature there varies greatly between day and night. Coat shall be taken in the morning and evening during the cold season. And the air is rather fresh in this mountain area. Tourists can really get in touch with nature.

2) Facilities: Phu Thai people used live in the stilt buildings which are made of wold (Fig. 2). There are some similar structures to the stilt houses. Usually, these stilt houses of Ban Phu had a few narrow windows and only one door in the front. Due to the hot and humid climate, the buildings in Ban Phu have the function and feature of preventing sunstroke summer and rain. In a general way, the first floor of the traditional Ban Phu stilt houses is not for living, it's always used for bath, cooking or livestock and poultry, in order to avoid inconvenience caused by water-logging during the rainy season and to prevent reptiles wounding such as local snakes wounding. Heavy grade roof are designed to increase the heat radiating area, to drain the rain quickly and to prevent the roof leakage.

Nowadays, brick houses also appear in the village, but most of them are of old style. There are more than 250 houses of Phu Thai people in Ban Phu Village. Over 50 traditional houses are selected to be the accommodation houses for home-stay. Ban Phu has been a home-stay village since 2006. Tourists who travel to $\mathrm{Ban} \mathrm{Phu}$ will get accommodation in the villagers' house, live and eat all the same as the locals. There are two temples in the village, an old temple and a newly-built temple. The old one is only used for important activities as it is so precious, and the new one is used for daily pray. Tourists can stay in traditional houses in Ban Phu, participate and look into the daily life and the cultural traditions of the Phu Thai people.

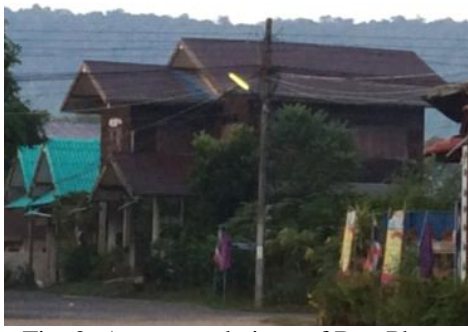

Fig. 2. Accommodations of Ban Phu.

3) Hospitality: Phu Thai people are enthusiastic and friendly to the tourists. They even regarded the tourists as their guests during the home-stay. They have a large welcome ceremony when the visitors come. Almost all the villagers gather together at the roadside and line up to greet the guests (Fig. 3). After that there is a praying and blessing ceremony. After praying, tourists are seated for dinner, and watching the performances of traditional Phu Thai singing and dancing.

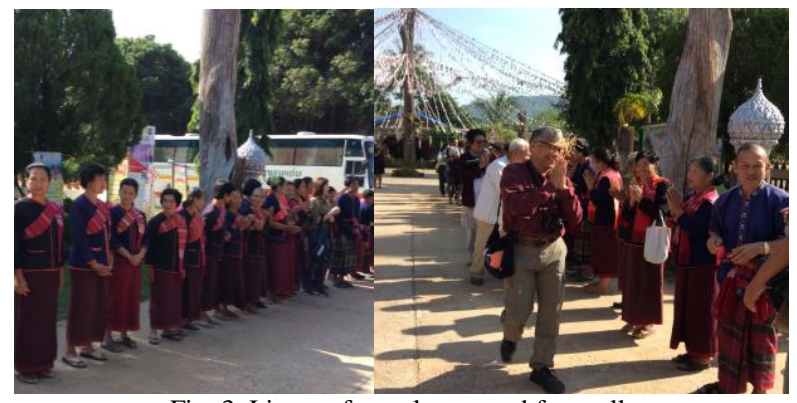

Fig. 3. Line up for welcome and farewell. 
The tourists are treated with local food such as sticky rice, fish and bamboo shoots, which are self-produced by Ban Phu Village. And villagers are also pleased to lead the visitors to go around the village when the visitors are interested. A farewell ceremony is held before the tourists leave as well.

4) Culture and custom: The Phu Thai people have multicultural heritage, such as dancing, music, cuisine, handwoven fabrics and handicraft works. Although the nearby communities have changed a lot, Ban Phu villagers still keep their traditional way of life. They go to the temple every morning, they catch fish from the river nearby, they use a traditional hand loom to weave and wear traditional clothes. Moreover, they have their own philosophy of sufficiency economy in six pillars. These consists the self-sufficient economic model of Ban Phu Village. The products of Phu Thai people are mainly traditional fabric, traditional clothes and handicraft works which are weaved by themselves (Fig. 4).
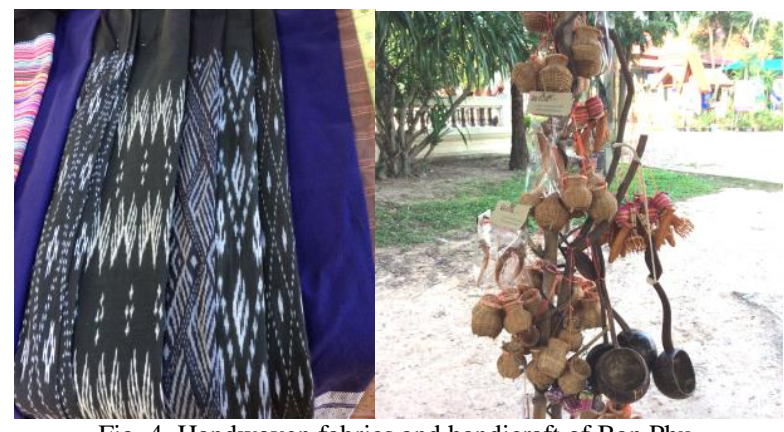

Fig. 4. Handwoven fabrics and handicraft of Ban Phu.

5) Ceremony: Visitors are welcomed with a traditional welcome dance and parade leading to the Community Learning Center of Ban Phu (Fig. 5). In the evenings there are cultural displays, for instance traditional cotton weaving, flirting with young girls, speaking Phaya, playing jacks, playing Saba, Phu Thai dancing, Bai Sri dancing, and children's performances from elementary age all the way through high school. At the center visitors learn about the identity of the local community and are able to taste the best foods brought in by locals. Finally, there is a Retro Dance. The ceremony ends at 9:30 p.m. In the morning visitors will be able to make merit and have breakfast with their host. After that visitors will study and observe examples of sufficient living and visit other group activities.

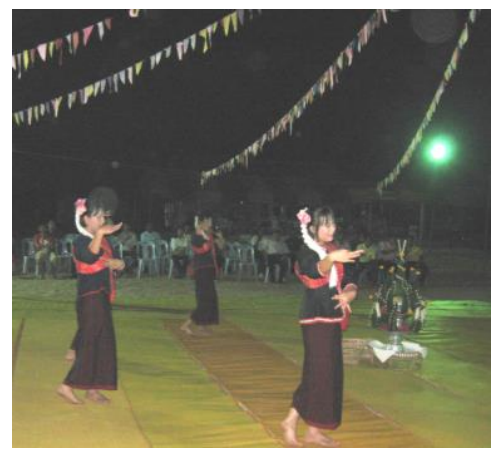

Fig. 5. Phu Thai dancing in the welcome ceremony.

6) Clothes: Phu Thai people have their own minority dress. The traditional female costume is barrel skirt called
Pasin and the man's apparel is called Payedme.

7) Foods: Food is served according to the season and availability, which includes bamboo shoots, chicken curry, chilli paste, spicy dips, fried fishes and vegetables grown organically. The most important staple food of Ban Phu is sticky rice, which is steamed in bamboo appliances and is put in a bamboo basket to keep it warm (Fig. 6).

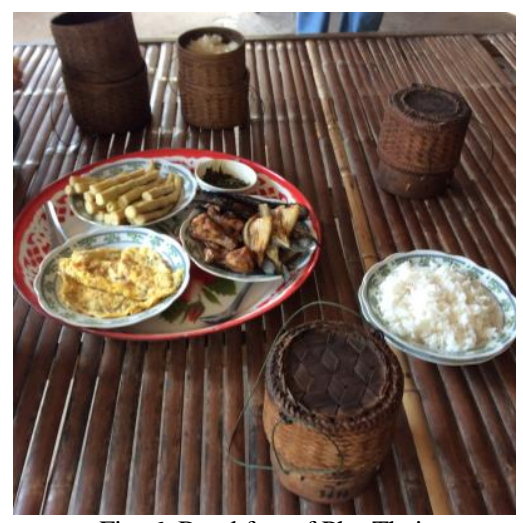

Fig. 6. Breakfast of Phu Thai.

The food is excellent and extremely fresh. The fishes is caught from the river nearby and the vegetables are from their own farmland. All the fresh meat and vegetables have been cooked over the wood-fuelled hearth, the result is the special and good tasted home-stay food: spicy, delicate and aromatic. The food prepared is put in a dustpan. All the family members and the guests sit around the dustpan to have meals together. It is artistic conception for visitors when having breakfast like this in a cool, misty morning in the mountains. Their food, house and lifestyle does not change a lot to suit or adapt the visitors, this makes the guests feel like a home-stay.

\section{B. The Tourism Market of Ban Phu}

There are a growing number of places in search of new forms of articulation between culture and tourism which can help to strengthen rather than water down local culture [8]. The cultural tourism can also raise the value accruing to local communities and improve the links between local creativity and tourism. Furthermore, the tourism industry has experienced the rapid growth in recent years in Thailand, which means that governments are grappling with the impacts upon both environments and cultures. According to this new trend, the demand for cultural travels will rapidly grow. In addition, the potential economic benefits of outbound Chinese tourists have led Thailand to simplify visa application procedures for Chinese citizens. Therefore, there is a chance for Ban Phu Village to meet the needs of a more sustainable cultural tourism in today's tourism industry.

Moreover, there are also some interesting opportunities in the inbound market, where expats, foreign visitors and the high-end segment of the Chinese market have a demand for creative and service-oriented packages. According to the United Nations World Tourism Organization (UNWTO), China has been and remains by far the fastest-growing tourism source market in the world over the past decade. Within this market, the inbound tourism industry has seen the largest growth. Outbound travel by Chinese citizens increased from 10 million in 2001 to 109 million in 2014 - a $16.6 \%$ increase. Reports from the China National Tourism 
Administration (CNTA) reveal that Thailand is still the favourite destination among Chinese outbound tourists (15\%) besides Hong Kong (17\%).

Thailand was the destination where Chinese tourists spent the most money in recent years. The main reason for tourists coming to Thailand was for sightseeing/leisure. China tourists are reluctant to travel to Thailand may include concerns about natural environment, food safety, security, and even cultural and language barriers [9]. The second most popular reason was for business. Another notable change is the recent development of the new visa policy on arrival in major cities throughout the country, making visiting Thailand easier than it once was. Thus, visitors from China have continuously increased.

With the development of China' economy, travel has become increasingly popular among Chinese citizens, and Chinese tourists travel abroad keep an increase each year. Most Chinese tourists start their preparation for travel from searching information, especially on the internet. And searching engines, travel website and SNS are the most popular tools among them. After the searching, they will compare all the information he found and here in this step, comments from others, news on other online news media and ranking are often taken seriously in consideration. Once they make decisions, they will make the payment for that and enjoy their travel. What needs to be pointed out is that in the era of Internet, the value of a tourist doesn't only mean money, but also his influence. His opinion, ideas and experience will probably influence people in his circle and the next tourist who search information online. And Chinese tourists are likely to trust the word from someone quite close to their situation in real life.

\section{Outlook and Forecast of the Tourism Market in Ban Phu}

Ban Phu is known for having a strong community. They have been honored as a model community. For instance, in 2006 they received an award from Her Royal Highness Princess Maha Chakri Sirindhorn for being a peaceful and happy village. In 2007 Ban Phu received an award for being a model community in the province of Mukadahan [7]. They have also been awarded the eighth Tourism Industries - trophy for having outstanding tourism.

The total number of outbound trips is projected to rise by $15 \%$ annually over the next few years. Outbound tourist expenditure is set to reach EUR 113.2 billion by 2017, while outbound trips should reach 28.5 million by 2020.1 [10].

In the next few years, an increasing number of foreign tourists are predicted to come from countries with a growing middle class and rising levels of disposable income, such as China, Japan, Indonesia, Laos or the Philippines [12]. The development of a national system of paid holidays, as well as the increase in express visa procedures or even exemptions in Thailand for Chinese tourists, should contribute to further growth in Thailand inbound tourism market.

\section{Developmental Opportunities and Challenges of Ban Phu}

According to the recent changes of tourism trends, it is obvious that visitors are more strongly involved in cultural activities than earlier. The rise of global culture impacts significantly upon tourism [11]. Needs and motivations are the engines of human conduct, which plays a fundamental part in the mechanics of tourism. According to the research paper [12], the subject of travel needs is:

(1) Relaxation (rest for active)

(2) Stimulation (stronger emotions)

(3) Social needs (family, friends)

(4) Self esteem (self development through cultural, nature or other activities)

(5) Self-realization (search for happiness)

We intend to introduce and highlight the most important types or in other words elements of cultural tourism from a thematic perspective grouped by the principles of the preferred activity [13]. According to our standardization we classify cultural tourism in the following way:

(1) Heritage tourism

(2) Cultural thematic routes

(3) Cultural city tourism, cultural tours

(4) Traditions, ethnic tourism

(5) Event and festival tourism

(6) Religious tourism, pilgrimage routes

(7) Creative culture, creative tourism

At present, Thailand's international tourist products tend to be old fashioned and highly structured. They have been largely designed for culture-oriented sightseeing tour groups. The itineraries have fixed tour routes and tour contents, which included activities, meals, shopping, and shows with little innovation. These kinds of products can no longer suit the demands of contemporary international tourists who are seeking more independence and greater flexibility and choice [14].

\section{1) Opportunities}

The Impact of Culture on Tourism it seems that worldwide almost 360 million International tourism trips were generated by cultural tourism in 2007 , accounting to around $40 \%$ of all global tourism[2]. Furthermore, the amount of money spent by a 'cultural tourist' is estimated to be as one third more on average than other tourists [15].

Increasingly, Chinese travelers are demanding a more personalized travel experience. Currently, $44 \%$ of travelers make their travel plans independently, and this figure is expected to grow to $50 \%$ in the future. Another opportunity for Ban Phu Village comes from the increasing number of investments by Chinese companies in Thailand assets.

In addition, as the tourist population becomes increasingly interested in the cultural values, there are plenty of opportunities for Thailand companies or Ban Phu Village in this sector [16].

Especially, accelerating the building of the Belt and Road can help promote the economic prosperity of the countries along the Belt and Road and regional economic cooperation; enhance cooperation in and expand the scale of tourism; jointly create competitive international tourist routes and products with Silk Road features; and make it more convenient to apply for tourist visa in countries along the Belt and Road.

Furthermore, the Sino-Thai high-speed railway project can become a new highlight in China-Thailand cooperation. Railway development in Thailand will facilitate smooth logistics and economic prosperity. This should push forward 
cooperation on the 21st-Century Maritime Silk Road cruise tourism program. This also will create even more opportunities for the development of Thailand and other Southeast Asian countries.

\section{2) Challenges}

(1) The infrastructure is imperfect. They don't have free Wi-Fi neither in the village nor in the house of the villagers. It's not convenient to connect with outside. They still lack of running water supply.

(2) Lack of Media publicity. Ban Phu Villagers had made a lot of effort for publicity, such as create a website, print fliers for the tourists, wrote and edited the book of Ban Phu. However, those are not enough for promoting external tourist market. The villagers should step up their advertising campaigns. The problem is that the website of Phu Thai is really hard to find, and Thai vision is difficult for foreign tourist to read.

(3) Language is also a problem for tourists. Phu Thai people have their own language--Phu Thai Language, some of them speak Isan Language, and some of them speak Thai Language. Few of the villagers who have ever worked in Taiwan can speak a little Chinese. Most of them speak neither English nor Chinese. It would be hard to communicate with the Chinese tourists if they only speak Thai.

(4) Shopping. The World Tourism organization released a report that shopping and tourism are still the key activity for Chinese tourists. Global retailers need to deal with the diversification of Chinese customers taste through a variety of ways. For Phu Thai people, they can design lots of different products for tourist. Such as food, clothes, decoration and so on.

(5) Transportation is not convenience. Phu Thai is a village in the countryside of Mukdahan Province, Thailand. It is far away from the towns near by as well as central Thailand.

(6) Accommodations. Some of the houses need to improve the living condition. Most of Chinese tourists like using hot water to take a shower. The food could be more diverse if possible. And the local food can be made to sale, such as Jewl.

(7) Activities. The tourists needs more participate in the cultural tourism. They can open classes for teaching dancing and folk songs, go to catch with the tourists etc.

\section{CONCLUSION AND SUGgestion}

In conclusion, Ban Phu community is a tourist attraction with good cultural resources, Ban Phu Village has potential to be developed as a cultural tourism village, and it also enables visitors to experience cultural experience in Ban Phu and generate more income to the community as well. However, it has a long way to go if it is going to open to Chinese or other international tourists. Here is the recommendation of five areas to tourism increasing its competitiveness and winning market:

(1) Knowing the customer

(2) A dedicated geographic strategy

(3) Ensuring to deliver quality tourism experiences

(4) A healthy aviation environment

(5) Strong partnerships between Government and industry

According to the tourism supply and problems of tourism needs of Ban Phu Village, the following suggestion shall be implement to develop the cultural tourism of Ban Phu Village:

(1) The government should increase investment in Ban Phu.

(2) Tourism propaganda should be strengthened.

(3) Local infrastructure construction shall be improved.

\section{ACKNOWLEDGMENT}

This research was supported by Faculty of Fine and Applied Arts, Khon Kaen University, Thailand. And I also would like to thank Ban Phu Village, Nong Sung, Mukdahan Province of Thailand, for the information supporting of this research and warm reception of our delegation.

\section{REFERENCES}

[1] G. Richards, Cultural Tourism in Europe, Wallingford: CABI, 1996.

[2] G. W. Richards, "The impact of culture on tourism Paris," Journal of Financial Stability, p. 159, 2009.

[3] R. Hewison, "Revising and implementing the marketing concept as it applies to tourism," Tourism Management, vol. 11, no. 3, pp. 195-205, 1998.

[4] T. O'Dell, “Tourist experiences and academic junctures,' Scandinavian Journal of Hospitality and Tourism, vol. 7, no. 1, pp. 34-45, 2007.

[5] M. Venema, An Introduction to the Tourism System, Edutour BV, 2011.

[6] T. Whelan, Ecotourism and Its Role in Sustainable Development, Nature Tourism, Managing for the Environment, Washington DC: Island Press, 1991.

[7] Cultural Office of Mukdahan, "Interview: Culture of Phu Thai minority," Data of Ban Phu Village, 2015.

[8] M. I. Evaristus, "The role of tourism in the conservation of cultural heritage in Kenya," Asia Pacific Journal of Tourism Research, vol. 9, no. 2, pp. 133-150, 2004

[9] D. Dredge, "Economy and culture: Cultural heritage tourism planning, Liangzhu, China," Asia Pacific Journal of Tourism Research, vol. 9, no. 4, pp. 405-422, 2004.

[10] MITC. (2015). Travel and tourism industry opportunities in Japan \& China. [Online]. Available: http://www.mitc.com/wp-content/uploads/2015/04/2015-Travel-and-T ourism-Resource-Guide-Japan-and-China.pdf

[11] P. Ho and B. McKercher, "Managing heritage resources as tourism products," Asia Pacific Journal of Tourism Research, vol. 9, no. 3, pp 255-266, 2004

[12] P. L. Pearce, "Perceived changes in holiday destinations," Annals of Tourism Research, 1982.

[13] C. Lee, "An investigation of factors determining the study abroad destination choice: A case study of Taiwan," Journal of Studies in International Education, vol. 18, no. 4, pp. 362-381, 2014.

[14] J. K. Sharma, Tourism Product and Services: Development Strategy and Management Options, New Delhi: Kanishka Publishers, 2007.

[15] G. Richards, "Tourism development trajectories - From culture to creativity? Tourism research and marketing, Barcelona," presented at the Asia-Pacific Creativity Forum on Culture and Tourism, Jeju Island, Republic of Korea, 3-5 June, 2009.

[16] C. Lee and S. Morrish, "Cultural values and higher education choices: Chinese families," Australasian Marketing Journal (AMJ), vol. 20, no. 1, pp. 59-64, 2012.

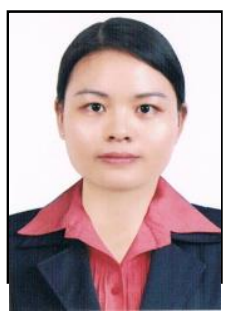

Liu Jiaxiu was born in Jiangxi Province of China in August, 1987. She finished her bachelor study majoring in teaching Chinese as a second language in Gannan Normal University, China, in 2009. She earned a master's degree of Mahasarakham University, Thailand, in cultural science in 2015. And she started doctoral study in arts and culture research in Khon Kaen University since the year 2015. 
She went to Thailand to teach Chinese in Bangkok in 2009, and became a supervising teacher for new-come Chinese teachers in Thai-Chinese Education Association Center in 2011. Driven from her interest in cross cultural communication, she worked on her MA in cultural studies at the Cultural Institute in Mahasarakham University. She has ever focused on the study of Isan Chinese teacher's life in an intercultural environment. At present, she is a Ph.D. candidate in Faculty of Fine and Applied Arts. Her research orientation is culturology and ethnology.

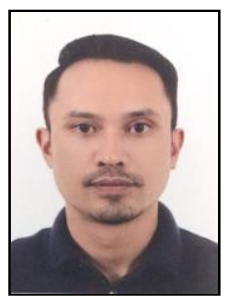

Pat Kotchapakdee was born in Khon Kaen, Thailand, on August 24, 1981. He received a bachelor's degree in music in 2002, a master's degree in education technology in 2005, and a $\mathrm{Ph} . \mathrm{D}$. in art and culture research in 2014 from Khon Kaen University.

He was a lecturer at the Faculty of Education at Khon Kaen University from 2003-2011 before transferring to his current position as lecturer at the university's International College (KKUIC). In addition to his main job, he is also a part-time lecturer at the Faculty of Fine and Applied Arts. Both his past and present academic research explores the arts, local wisdom, and cultural background of various indigenous groups of people in the ASEAN region. In 2016, he received a research grant from the National Geographic Society for his project in progress titled "Lost tattoos and the stories behind them".

Also in the year 2016, Dr. Kotchapakdee received an award for his publication "Thai influence on the Lao pop music industry: History, repercussion and the future" at the Empowering Network for International Thai and ASEAN Studies (ENITAS) conference held at Chulalongkorn University in Bangkok.

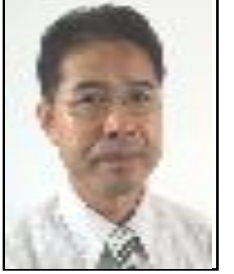

Homhuan Buarabha was born in Loei, Thailand, on 11 June, 1964. He got the bachelor's degree in philosophy from the University of Mahamakut Buddhist University, Bangkok ,Thailand, in1989; the MA. in philosophy from Kurukshetra University, Haryana, India, in 1997; Ph.D. in philosophy, Kurukshetra University, Haryana, India, in 2002.

He is now an assistant professor in Faculty of Humanities and Social Sciences, Khon Kaen University, Khon Kaen, Thailand. Dr. Homhuan has had a lot of academic achievements in culture and philosophy. His field of study is: philosophy, religions and culture. Dr. Homhuan and his team have redacted the book of philosophy (Homhuan Buarabha and Faculty of Humanities and Social Sciences. Introduction to Philosophy (Textbook), Khon Kaen University, Thailand, 2006), and he has edited the book Legacy Arts of Isan (Homhuan Buarabha (ed.), Legacy Arts of Isan, Cultural Office of Khon Kaen University, 2008.) etc. 